\title{
Short-Term Exposure to Haze Air Pollution Induces Acute Airway Inflammation and Lung Function Reduction in Healthy Adult Subjects
}

Haibin Li ${ }^{1,2}$, Yanqin Liu ${ }^{3}$, Sanqiao Yao ${ }^{1,2}$, Yuefei Jin ${ }^{4}$, Yixin Luo ${ }^{1,2}$, Wenyang Li ${ }^{1,2}$, Chengyu Song ${ }^{1,2}$, Chonglun Liu ${ }^{1,2}$, Ziye Wang ${ }^{1,2}$ and Weidong $\mathrm{Wu}^{1,2 *}$

${ }^{1}$ Department of Occupational and Environmental Health, PR China

${ }^{2}$ Henan International Collaborative Laboratory for Health Effects and Intervention of Air Pollution, School of Public Health, PR China

${ }^{3}$ School of Foreign Languages, Xinxiang Medical University, Xinxiang, Henan Province 453003, PR China

${ }^{4}$ Department of Epidemiology, College of Public Health, Zhengzhou University, Henan Province 450001, PR China

\begin{abstract}
Haze air pollution with high levels of PM has frequently took place in many areas of China in the past few years. However, the health effect of shirt-term exposure to haze air pollution has not been thoroughly characterized. This study aimed to determine the acute effect of haze exposure on respiratory system of healthy adult subjects, specifically on airways and lung function. Thirty healthy adult subjects were recruited and airway inflammation and lung function alterations examined under control and haze air pollution $(157.33 \mu \mathrm{g} / \mathrm{m}$ for mean concentration of PM ) conditions, respectively. Airway inflammation was assessed by sputum induction while lung function was measured using spirometry. It was shown that 24-h exposure to haze air pollution could increase the levels of inflammatory mediators including interleukin-6 (IL-6), IL-8, and tumor necrotic factor- $\alpha$ (TNF- $\alpha$ ), as well as the percentages of eosinophils, neutrophils, and lymphocytes in the sputum $(<0.05)$. In contrast, the proportion of macrophages in the sputum from haze-exposed subjects decreased significantly $(<0.05)$. In addition, short-term exposure to haze could decrease forced vital capacity (FVC), forced expiratory volume in the first second (FEV), vital capacity (VC), and maximum voluntary ventilation (MVV), but not FEV1/FVC. In summary, short-term exposure of healthy adult subjects to haze air pollution induces airway inflammation and lung function impairment.
\end{abstract}

Keywords: Haze; Airway inflammation; Lung function; Sputum induction

Abbreviations: IL: Interleukin; TNF- $\alpha$ : Tumor Necrotic Factor- $\alpha$; FVC: Forced Vital Capacity; FEV: Forced Expiratory Volume in the first second; VC: Vital Capacity; MVV: Maximum Voluntary Ventilation; PRD: Pearl River Delta; O: Ozone; PM, Particulate Matter; PM: PM with an aerodynamic diameter less than $2.5 \mu \mathrm{m}$; DTT: Dithiothreitol; AQI: Air Quality Index; ELISA: Enzyme-Linked Immunosorbent Assay; QFF: Quartz Fiber Filters; PBS: Phosphate Buffer Solution.

\section{Introduction}

Rapid economic development and urbanization in China over the last few decades has led to increased occurrence of haze air pollution in some regions, especially in North and Central China Plains, the Yangtze River Delta and the Pearl River Delta (PRD) [1]. A 52-year record between 1954 and 2006 showed that annual haze days in Guangzhou, a central city in PRD, increased rapidly from a few days annually between 1954 and 1972, to remaining fairly constant 150 days annually since 1980 [2]. Fewer than $1 \%$ of the 500 largest cities in China met the air quality standards recommended by the World Health Organization, and 7 of these cities were ranked among the 10 most polluted cities in the world [3]. Haze is an extreme episode of air pollution that is characterized by decreased visibility less than 10 kilometers and high concentrations of particulate matter (PM) and gaseous pollutants, of which PM (PM with an aerodynamic diameter less than $2.5 \mu \mathrm{m}$ ) is the major component [4]. Haze air pollution in China is mainly caused by coal burning, vehicle exhaust, industrial and road dust, smokestacks, and among others. These pollutants can reduce the atmospheric visibility by scattering and absorbing ambient light [5]. Photochemical smog, another component of haze, also affects the visibility as well as increases ambient levels of ozone $(\mathrm{O})[6]$. Moreover, high ambient $\mathrm{O}$ concentration may increase the production of nitrogen dioxide which may absorb blue light in the air, making air appearance brown, hence reducing visibility [7].

Continuous haze weather has become a serious threat to sustainable development of China. More importantly, environmental and health problems related to haze have received considerable attention from the government and public [8]. In line with public concerns, a few studies have explored the health effects of haze exposure in China. For example, a previous study in Guangzhou showed that haze significantly increased mortality risk and this effect appeared to be dominated by particulate mass and modified by season and individualspecific factors [7]. A recent study compared the number of cases of acute cardiovascular, cerebrovascular, and respiratory diseases in Beijing Emergency Center between 2006 and 2013, with haze data from Beijing Observatory showed that the average number of cases per day for all three diseases was higher on hazy days than on non-hazy days [9]. Another study examining short-term mortality risk during haze events in Hong Kong demonstrated that a regular hazy day (lag 0) had higher all-cause mortality risk than a day without haze [10]. Additionally, a time-series study reported that the mortality risk of haze and PM peaked on the second day and could last for three days [11]. The excess risk of haze at lag 0-2 days on total mortality, cardiovascular and respiratory mortality was $7.76 \%, 7.73 \%$ and $17.77 \%$, respectively. Greater effects of haze air pollution were observed during the cold season than in the warm season, and the elderly were at higher risk compared to youths [11].

*Corresponding author: Weidong $\mathrm{Wu}, \mathrm{PhD}$, School of Public Health, Xinxiang Medical University, 601 Jinsui Street, Xinxiang, Henan Province 453003, PR China, Tel: 863733831051 E-mail: wdwu2013@126.com

Received January 10, 2018; Accepted February 20, 2018; Published March 05, 2018

Citation: Li H, Liu Y, Yao S, Jin Y, Luo Y (2018) Short-Term Exposure to Haze Air Pollution Induces Acute Airway Inflammation and Lung Function Reduction in Healthy Adult Subjects. J Environ Anal Toxicol 8: 555. doi: 10.4172/2161. 0525.1000555

Copyright: ( $2018 \mathrm{Li} \mathrm{H}$, et al. This is an open-access article distributed under the terms of the Creative Commons Attribution License, which permits unrestricted use, distribution, and reproduction in any medium, provided the original author and source are credited. 
Citation: Li H, Liu Y, Yao S, Jin Y, Luo Y (2018) Short-Term Exposure to Haze Air Pollution Induces Acute Airway Inflammation and Lung Function Reduction in Healthy Adult Subjects. J Environ Anal Toxicol 8: 555. doi: 10.4172/2161-0525.1000555

Page 2 of 5

In contrast to previous studies on haze-associated morbidity and mortality, this study mainly focused on the subclinical inflammatory effects of haze air pollution on airways of healthy adult subjects since airway inflammation is a common and essential event in the pathogenesis of diverse lung diseases. Assessment of airway inflammation was performed using sputum induction. In addition, the impact of short-term exposure to haze air pollution on lung function was also evaluated using spirometry.

\section{Materials and Methods Reagents}

Dithiothreitol (DTT) and sodium chloride (analytically pure) were purchased from Sigma Company, USA. Enzyme-linked immunosorbent assay (ELISA) kits were obtained from Shenzhen Xin bo-sheng Biotechnology Company, China.

\section{Subjects}

The study subjects from Xinxiang Medical University, China, included thirty healthy nonsmoking college students (13 females and 17 males; mean age $20 \mathrm{yrs}$ ). None of the subjects had a history of allergy, asthma or any other pulmonary diseases and none had experienced any respiratory tract infection in last 4 weeks prior to and during the study period. The protocol of this study was reviewed and approved by the Medical Ethics Committee of Xinxiang Medical University. The consent form was reviewed and signed by each subject prior to the examination. As a part of the screening procedure for participation in the study, all subjects were tested as to their ability to produce sputum on induction with hypertonic saline.

\section{Study design}

Self-controlled method was used in this study. Briefly, 30 healthy subjects were naturally exposed to two air pollution conditions (herein designated as control and haze condition), respectively, prior to sputum induction. In this study, the control condition referred to the condition under which mean concentrations of PM had been less than $75 \mu \mathrm{g} / \mathrm{m}$ for a consecutive of five days just before sputum induction. Air quality under this condition was classified as "good" according to China Air Quality Index (AQI). In contrast, the haze condition specified in this study referred to the condition under which the 24-h mean concentration of PM was $157.33 \mu \mathrm{g} / \mathrm{m}$ before sputum induction. And prior to haze air quality had been "good" for a consecutive of seven days (to minimize the residual effects of previous haze exposure). In other words, the subjects were exposed to haze condition for approximately $24 \mathrm{~h}$ before sputum induction.

\section{Determination of ambient PM concentrations}

Ambient levels of PM under control or haze condition were determined using a large-flow particle sampler (KC-1000, Qingdao Lao Mountain Electronic Instrument Company, Qingdao, China) located on the top of the Research Building on campus, where dorms, classrooms, and playgrounds were situated. Levels of ambient PM were monitored according to the guideline of Ambient Air Quality Standard from China's Ministry of Environmental Protection. Quartz fiber filters (QFF) were provided by the sampler manufacturer and stored in a thermostatic drier and weighed $24 \mathrm{~h}$ before and after sampling for condition equilibrium. Levels of PM were calculated based on the difference in weights of QFF before and after sampling and the corresponding air volume.

\section{Sputum induction}

Sputum induction was performed after exposure of the subjects to control and haze condition, respectively, according to the protocol published previously [12]. In brief, the subjects were instructed to mouthwash with water. Sputum induction was performed by stepwise inhalations of $7 \mathrm{~min}$ each with increasing concentrations of sodium chloride $(3 \%, 4 \%$ and $5 \%)$ in healthy individuals nebulized by an ultrasonic nebulizer (YHMED WH-2000, Guangdong, China). After mouth washing andblowing the nose again, individuals were advised to give a deep cough from the chest and without scraping the throat, and passively bring it past the throat into the sterile cup. Sputum was processed immediately. During the sputum induction, the FEV1 (force expired volume in one second) was monitored to make sure not fallen more than $10 \%$. Otherwise the induction needed to be terminated.

\section{Sputum processing}

After careful isolation of sputum solid phase, total weight was determined and recorded. Tohomogenize the solid phase of the sputum samples by cleavage of disulphide bonds of mucin glycoproteins, two volume parts of sputolysin reagent containing $10 \mathrm{~g} / \mathrm{L}$ DTT and $100 \mathrm{mM}$ phosphate buffer solution (PBS, pH 7.0) were added. After vortexing briefly, the mixture was incubated at $37^{\circ} \mathrm{C}$ and vortexed every $10 \mathrm{~min}$ until the sputum was homogenized, in total no longer than $60 \mathrm{~min}$. Then the digested sputum was filtered through a $48 \mu \mathrm{m}$ nylon screen into a $15 \mathrm{ml}$ centrifuge tube and then centrifuged at $2000 \mathrm{rpm}$ for 10 min to separate supernatant and cell pellet. The resulting sputum cells of the different inhalation steps $(3 \%, 4 \%$ and $5 \%$ saline) were pooled and analyzed for differential leukocyte counts. Aliquots of sputum supernatant were collected and immediately frozen and stored at $-80^{\circ} \mathrm{C}$ for future cytokine measurement.

\section{Cell staining}

The resulting cell pellet was re-suspended into PBS. For differential cell counts, slides were prepared using cytospins. After drying at room temperature, the cells were subjected to $\mathrm{H} \& \mathrm{E}$ staining. 400 cells were counted and the percentages of eosinophils (EO), neutrophils $(\mathrm{N})$, lymphocytes (L), and macrophages $(\mathrm{M})$ were calculated. Contamination of squamous cells was less than $10 \%$ in all samples.

\section{Measurement of inflammatory mediators with ELISA}

Levels of interleukin (IL)-6, IL-8, and tumor necrosis factor-a (TNF- $\alpha$ ) in the supernatants of induced sputum were measured with ELISA following the manufacturer's instruction.

\section{Measurement of lung function}

Pulmonary function tests were performed at the laboratory. Pulmonary function was measured with a Chestgraph HI-701 (Chest Co., Tokyo, Japan). While sitting, the subjects placed the respiratory apparatus in their mouths and inhaled and exhaled as much as possible. The spirometry was performed at least three times. The parameters of lung function included force vital capacity (FVC), FEV1, FEV1/FVC, vital capacity (VC) and maxmum voluntary ventilation (MVV). These parameters were expressed as percentages of the predictive values.

\section{Statistical analysis}

Data are presented as mean \pm SD. Paired t test was performed to analyze the levels of inflammatory mediators, inflammatory cell numbers and lung function, with the overall $\alpha$ level set at 0.05 . 
Citation: Li H, Liu Y, Yao S, Jin Y, Luo Y (2018) Short-Term Exposure to Haze Air Pollution Induces Acute Airway Inflammation and Lung Function Reduction in Healthy Adult Subjects. J Environ Anal Toxicol 8: 555. doi: 10.4172/2161-0525.1000555

Page 3 of 5

\section{Results}

\section{Haze exposure increases levels of inflammatory mediators in airways of healthy subjects}

Sputum induction was well tolerated by all subjects. As shown in Figure 1, short-time exposure to haze could induce significant increase in levels of inflammatory mediators including TNF- $\alpha$, IL-6 and IL-8 in sputum compared with control condition, implying that short-term exposure to haze could trigger inflammatory response of airways in healthy subjects.

\section{Effect of haze exposure on inflammatory cells in airways of healthy subjects}

As shown previously, short-term exposure to haze air pollution could induce the increase in inflammatory mediators. To corroborate this observation, we examined the effect of haze exposure on sputum cellularity. Differential cell counts in sputum of the subjects exposed to control and haze conditions are presented in Table 1. It was shown that haze exposure significantly increased the percentages of eosinophils (EO), neutrophils (N), and lymphocytes (L) in sputum compared with control. Intriguingly, haze exposure posed little effect on the percentage of macrophages $(\mathrm{M})$. Overall, these results in combination of inflammatory mediator data indicated that short-term exposure to haze could induce airway inflammation of healthy subjects.

\section{Haze exposure impairs lung function}

Lung function is an objective marker of respiratory health and a predictor of cardiorespiratory morbidity and mortality [13]. The

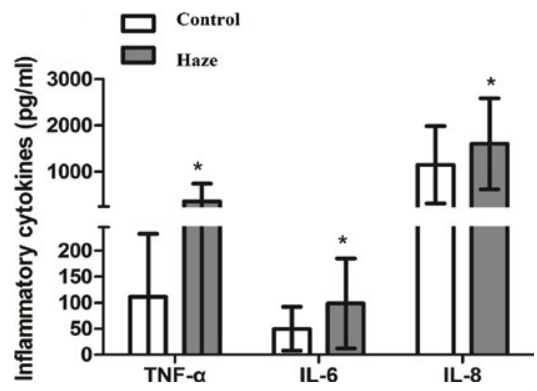

Figure 1: Haze exposure increases the levels of the inflammatory mediators in sputum of the subjects. The supernatants of induced sputum from healthy subjects $(n=30)$ exposed to control and haze air pollution, respectively, were collected and subjected to measurement of inflammatory mediators with ELISA. ${ }^{*} P<0.05$, compared to control.

\begin{tabular}{|c|c|c|c|c|}
\hline Group & EO & N & L & M \\
\hline Haze & $0.66 \pm 0.31^{*}$ & $33.74 \pm 5.29^{*}$ & $2.46 \pm 0.34^{*}$ & $54.74 \pm 4.81^{*}$ \\
\hline control & $0.58 \pm 0.27$ & $31.02 \pm 3.84$ & $2.29 \pm 0.25$ & $57.18 \pm 5.18$ \\
\hline
\end{tabular}

${ }^{*}$ Compared to control condition, $P<0.05$; Note: EO: eosinophils; N: neutrophils; L: lymphocytes; M: macrophages

Table 1: Percentages of inflammatory cells in sputum of the subjects exposed to haze or control condition (\%).

\begin{tabular}{|c|c|c|c|c|}
\hline Group & FVC(\%) & FEV $_{\mathbf{1}}(\mathbf{\%})$ & FEV $_{\mathbf{1}}$ /FVC & VC(\%) \\
\hline Haze & $101.14 \pm 12.33^{*}$ & $99.20 \pm 9.84^{*}$ & $0.99 \pm 0.09$ & $103.45 \pm 10.90^{*}$ \\
\hline control & $102.98 \pm 11.97$ & $100.92 \pm 10.84$ & $0.98 \pm 0.06$ & $125.25 \pm 14.65^{*}$ \\
\hline
\end{tabular}

*Compared to control condition, $P<0.05$

Table 2: Lung function of the subjects exposed to haze or control condition. impact of short-term haze exposure on lung function was assessed using spirometry. As shown in Table 2, exposure of healthy subjects to haze air pollution resulted in decreased FVC, FEV1, VC, and MVV but not FEV1/FVC, implying that acute haze exposure could impair lung function.

\section{Discussion}

Haze air pollution episodes occurred frequently in many areas of China including Xinxiang, wherein this study was performed. The main composition of haze, namely PM, could enter and deposit on human airways. Long-term exposure to haze has been proposed to induce lung cancer [14]. In this study we examined the acute effect of haze on respiratory system and found that short-term exposure to haze air pollution could induce airway inflammation and impairment of lung function of healthy subjects. Our findings indicated that shortterm exposure to haze could irritate upper respiratory tract and cause nose and throat symptoms (Data not shown). The cause of this effect was assumed to be related to physical and chemical properties of haze since it was composed of various sizes of particles, chemicals and biological pollutants, and can interact with capillary-abundant mucous membrane through physical action or dissolved chemicals.

In addition to irritant effect, this study mainly investigated subclinical inflammation of airways in healthy subjects exposed to haze air pollution by means of sputum induction. Analysis of induced sputum results has shown them to correlate well with data obtained from bronchial wash and bronchoalveolar lavage [15,16]. Induced sputum has been proved to be valuable in evaluation of the airway effects of air pollutants including $\mathrm{O}$ [15] and nitrogen dioxide [17]. The results from this study indicated that haze exposure could increase the levels of IL-6, IL-8, and TNF- $\alpha$ in the supernatants of induced sputum, implying that acute haze exposure could induce airway inflammation. During the pathogenesis of inflammation, TNF- $\alpha$ can promote adherence of neutrophils and eosinophils to endothelial cells, facilitating their migration towards the inflammatory area and enhancing the cytotoxicity [18]. IL-8 is a member of chemokine family, it can attract a variety of inflammatory cells to infiltrate into the inflammation area. Thus, both TNF- $\alpha$ and IL- 8 play an important role in the process of inflammation [19]. Meanwhile, IL-6 can strengthen the effects of all kinds of inflammatory mediators and prompt the aggregation of the inflammatory cells. These findings are similar to the results obtained from the previous study with sand storm, which showed increased sputum levels of TNF- $\alpha$, IL- 6 and IL- 8 induced by sand storm [20].

Induced sputum cell counts provide a relatively noninvasive method to evaluate the presence, type, and degree of inflammation in the airways of the lungs induced by pro-inflammatory and antiinflammatory stimuli [21-25]. The cellular inflammatory response to air pollution in humans is the subject of current investigation and multiple studies have demonstrated that both $\mathrm{O}$ and endotoxin exposure augment the influx of neutrophils in the airway [26-28]. Previous study has showed that the subjects exposed to heavier air pollution had more increases in alveolar phagocytes, neutrophils, and lymphocytes, but not in eosinophils and bronchial epithelial cells [29]. In contrast, 
Citation: Li H, Liu Y, Yao S, Jin Y, Luo Y (2018) Short-Term Exposure to Haze Air Pollution Induces Acute Airway Inflammation and Lung Function Reduction in Healthy Adult Subjects. J Environ Anal Toxicol 8: 555. doi: 10.4172/2161-0525.1000555

Page 4 of 5

in this study, we observed that haze exposure could increase the percentage of inflammatory cells including eosinophils, neutrophils, and lymphocytes in sputum of healthy subjects. Interestingly, the percentage of macrophages in sputum of haze-exposed subjects appeared lower than that in sputum of the same group of subjects exposed to control condition. The underlying mechanisms for hazeinduced cellular outcomes in airways remain to be determined.

Lung function, specifically FVC and FEV, is considered as one of the major and early indicators of respiratory and systemic inflammation, and associated with cardiorespiratory morbidity and mortality [30]. The various spirometric indices reflect airflow characteristics of different airways. In general FEV1 reflects the caliber of both large and small airways and is a reliable indicator of airflow limitation [31]; FVC reflects lung volume and is used to diagnose and monitor lung diseases; The FEV1/FVC ratio, also called Tiffeneau-Pinelli index, reflects expiratory power and overall resistance to air movement in the lungs. Previous epidemiological studies with adults have shown that a $10 \mu \mathrm{g} / \mathrm{m}$ increase in PM was associated with a 3.4\% decrease in FVC in a cross-sectional analysis, even after adjusting for cigarette use [32,33]. Higher concentrations of previous-day ambient PM were associated with approximately $20 \mathrm{~mL}$ lower FEV and FVC in nonsmoking adults in the Framingham Heart study [34], and long-term exposure to higher concentrations of PM (yearly levels) was associated with lower FEV and a faster rate of lung function decline [35]. In this study, we observed that haze exposure could cause modest decrease in FVC, FEV, VC, and MVV. It should be noted that though the absolute changes in lung function are of relatively low magnitude, prior research has shown that decreases in FEV are associated with all-cause mortality [36,37], and that lower lung function is associated with higher rates of cardiovascular disease $[38,39]$. In this study, we observed that shortterm exposure to haze posed minimal effect on FEV1/FVC, which may be due to short study duration, in which the lung presents potent compensatory function.

\section{References}

1. Zhang XY, Wang YQ, Niu T (2012) Atmospheric aerosol compositions in China: spatial/temporal variability, chemical signature, regional haze distribution and comparisons with global aerosols. Atmos Chem Phys 12: 779-799.

2. Deng $X$, Tie $X$, Zhou $X, B i X(2008)$ Long-term trend of visibility and its characterizations in the Pearl River Delta (PRD) region, China. Atmos Environ 42: 1424-1435.

3. Zhang YL, Cao F (2015) Fine particulate matter (PM2.5) in China at a city level. Sci Rep 5: 14884.

4. Vingarzan R, Li SM (2006) The Pacific 2001 air quality studyesynthesis of findings and policy implications. Atmos. Environ 40: 2637-2649.

5. Sloane C, White W (1986) Visibility: an evolving issue. Environ Sci Technol 20: 760-766.

6. Agarwal AK, Singh AP, Lukose J, Gupta T (2015) Characterization of exhaust particulates from diesel fueled homogenous charge compression ignition combustion engine. J Aerosol Sci 58: 71-85.

7. Liu T, Zhang YH, Xu YJ, Lin HL, Xu XJ, et al. (2014) The effects of dusthaze on mortality are modified by seasons and individual characteristics in Guangzhou, China. Environ Pollut 187: 116-123.

8. Zhang Z, Wang J, Chen L, Chen X, Sun G (2014) Impact of haze and air pollution-related hazards on hospital admissions in Guangzhou, China. Environ Sci Pollut Res Int 21: 4236-4244.

9. Zhang JJ, Cui MM, Fan D, Zhang DS, Lian HX, et al. (2015) Relationship between haze and acute cardiovascular, cerebrovascular, and respiratory diseases in Beijing. Environ Sci Pollut Res Int 22: 3920-3925.
The precise mechanisms as to how haze may influence airway inflammation and lung function remain unknown. Studies have suggested that PM may mediate adverse health effects via the generation of reactive oxygen species [40-42], activation of cell signaling pathways, and alterations of respiratory tract barrier function and antioxidant defenses, all of which may lead to airway inflammation and changes in pulmonary function.

\section{Conclusions}

Haze air pollution is a mixture of diverse air pollutants, of which PM is a major component. Documented studies have investigated the association of haze exposure with mortality and morbidity risks. This study mainly investigated subclinical effects of short-term exposure to haze on healthy subjects. It was shown that exposure to haze could induce acute airway inflammation and reduce lung functions. Therefore, it is suggested that proper protection measures should be taken on haze days even for healthy people. Due to the complexity of air pollutant components in haze weather, the mechanisms of hazeinduced adverse effect remain to be elucidated.

\section{Acknowledgements}

This study was supported by the National Key R\&D Program of China (2017YFD0400301, 2016YFC0900803), the National Natural Science Foundation of China $(81573112 ; 81373030)$, Key Science and Technology Research Program of Henan Province Education Department (14A330004), and National Training Program of University Student Innovation and Entrepreneurship of Local Colleges and Universities (201410472002, 201510472009). Mention of trade names or commercial products does not constitute endorsement or recommendation for use.
10. Ho HC, Wong MS, Yang L, Shi W, Yang J, et al. (2017) Spatiotempora influence of temperature, air quality, and urban environment on cause-specific mortality during hazy days. Environ Int 112: 10-22.

11. Gu S, Yang J, Woodward A, Li M, He T, et al. (2017) The short-term effects of visibility and haze on mortality in a coastal city of China: a time-series study. Int J Environ Res Public Health 14: E1419.

12. Bennett WD, Alexis NE, Almond M, Herbst M, Zeman KL, et al. (2014) Effect of inhaled endotoxin on mucociliary clearance and airway inflammatio $n$ in mild smokersand nonsmokers. J Aerosol Med Pulm Drug Deliv 27: 459-465.

13. Sin DD, Wu L, Man SF (2005) The relationship between reduced lung function and cardiovascular mortality: a population-based study and a systematic review of the literature. Chest 127: 1952-1959.

14. Lin YC, Hsu SC, Chou CC, Zhang R, Wu Y, et al. (2016) Wintertime haze deterioration in Beijing by industrial pollution deduced from trace metal fingerprints and enhanced health risk by heavy metals. Environ Pollut 208: 284-293.

15. Fahy JV, Wong H, Liu J, Boushey HA (1995) Comparison of samples collected by sputum induction and bronchoscopy from asthmatic and healthy subjects. Am J Respir Crit Care Med 152: 53-58.

16. Grootendorst DC, Sont JK, Willems LN, Kluin-Nelemans JC, Van Krieken $\mathrm{JH}$, et al. (1997) Comparison of inflammatory cell counts in asthma: induced sputum vs bronchoalveolar lavage and bronchial biopsies. Clin Exp Allergy 27: 769-779.

17. Vagaggini B, Paggiaro PL, Giannini D, Franco AD, Cianchetti S, et al. (1996) Effect of short-term NO2 exposure on induced sputum in normal, asthmatic and COPD subjects. Eur Respir J 9: 1852-1857. 
Citation: Li H, Liu Y, Yao S, Jin Y, Luo Y (2018) Short-Term Exposure to Haze Air Pollution Induces Acute Airway Inflammation and Lung Function Reduction in Healthy Adult Subjects. J Environ Anal Toxicol 8: 555. doi: 10.4172/2161-0525.1000555

18. Walther W, Kobelt D, Bauer L, Aumann J, Stein U (2015) Chemosensitization by diverging modulation by short-term and long-term TNF- $\alpha$ action on ABCB1 expression and NF-KB signaling in colon cancer. Int J Onco 147: 2276-2285.

19. Driscoll KE, Carter JM, Hassenbein DG, Howard B (1997) Cytokines and particleinduced inflammatory cell recruitment. Environ Health Perspect 105: 1159-1164.

20. Huang $X L$, Jin $Y$ (2004) The influence of sand storm PM2.5 and PM10 on rat alveolar macrophage inflammatory factor secretion. J Environ Health 21: $38-40$.

21. Thomas PS, Yates DH, Barnes PJ (1999) Sputum induction as a method of analyzing pulmonary cells: reproducibility and acceptability. J Asthma 36: 335341.

22. Fahy JV, Boushey HA, Lazarus SC, Cherniack RM, Chinchilli VM, et al. (2001) Safety and reproducibility of sputum induction in asthmatic subjects in a multicenter study. Am J Respir Crit Care Med 163: 1470-1475.

23. Fireman E (2001) Induced sputum: opening a new window to the lung. Sarcoidosis Vasc Diffuse Lung Dis 18: 263-271.

24. Belda J, Leigh R, Parameswaran K, O'Byrne PM, Sears MR, et al. (2000) Induced sputum cell counts in healthy adults. Am J Respir Crit Care Med 161:475-478

25. Pavord ID, Pizzichini MM, Pizzichini E, Hargreave FE (1997) The use of induced sputum to investigate airway inflammation. Thorax 52: 498-501.

26. Yan Z, Wang J, Li J, Jiang N, Zhang R, et al. (2015) Oxidative stress andendocytosis are involved in upregulation of interleukin-8 expression in airway cells exposed to PM2.5. Environ Toxicol 31: 1869-1878.

27. Hernandez ML, Lay JC, Harris B, Esther CR, Jr, Brickey WJ, et al. (2010) Atopic asthmatic subjects but not atopic subjects without asthma have enhanced inflammatory response to ozone. J Allergy Clin Immunol 126: 537-544.

28. Krishna MT, Madden J, Teran LM, Biscione GL, Lau LC, et al. (1998) Effects of $0.2 \mathrm{ppm}$ ozone on biomarkers of inflammation in bronchoalveolar lavage fluid and bronchial mucosa of healthy subjects. Eur Respir J 11: 1294-1300.

29. Nobutomo K (1978) Air pollution and cytological changes in sputum. Lancet 1: $523-526$

30. Adam M, Schikowski T, Carsin AE, Cai Y, Jacquemin B (2015) Adult lung function and long-term air pollution exposure. ESCAPE: multicentre cohort studyand meta-analysis. Eur Respir J 45: 38-50.

31. Goel A, Goyal M, Singh R, Verma N, Tiwari S (2015) Diurnal variation in peak expiratory flow and forced expiratory volume. J Clin Diagn Res 9: CC05.
32. Künzli N, Ackermann-Liebrich $U$, Brändli $O$, Tschopp JM, Schindler $C$, et al. (2000) Clinically "small" effects of air pollution on FVC have a large public health impact. Swiss Study on Air Pollution and Lung Disease in Adults (SAPALDIA)-team. Eur Respir J 15: 131-136.

33. Ackermann-Liebrich U, Leuenberger P, Schwartz J, Schindler C, Monn C, et al. (1997) Lung function and long term exposure to air pollutants in Switzerland. Study on Air Pollution and Lung Diseases in Adults (SAPALDIA) Team. Am J Respir Crit Care Med 155: 122-129.

34. Rice MB, Ljungman PL, Wilker EH, Gold DR, Schwartz JD, et al. (2013) Shortterm exposure to air pollution and lung function in the Framingham Heart Study. Am J Respir Crit Care Med 188: 1351-1357.

35. Rice MB, Ljungman PL, Wilker EH, Dorans KS, Gold DR, et al. (2015) Longterm exposure to traffic emissions and fine particulate matter and lung function decline in the Framingham heart study. Am J Respir Crit Care Med 191: 656664.

36. Schünemann HJ, Dorn J, Grant BJ (2000) Pulmonary function is a long-term predictor of mortality in the general population: 29-year follow-up of the Buffalo Health Study. Chest 118: 656-664.

37. Miller MR, Pedersen OF, Pedersen OF, Lange P, Vestbo J (2009) Improved survival prediction from lung function data in a large population sample. Respir Med 103: 442-428.

38. Georgiopoulou VV, Kalogeropoulos AP, Psaty BM, Rodondi N, Bauer DC et al. (2011) Lung function and risk for heart failure among older adults: the Health ABC Study. Am J Med 124: 334-341.

39. Sin DD, Wu L, Man SF (2005) The relationship between reduced lung function and cardiovascular mortality: a population-based study and a systematic review of the literature. Chest 127: 1952-1959.

40. Kelly FJ, Fussell JC (2012) Size, source and chemical composition as determinants of toxicity attributable to ambient particulate matter. Atmos Environ 60: 504-526.

41. Hogervorst JG, de Kok TM, Briedé JJ, Wesseling G, Kleinjans JC, et al. (2006) Relationship between radical generation by urban ambient particulate matter and pulmonary function of school children. J Toxicol Environ Health A 69 : 245-262.

42. Janssen NA, Strak M, Yang A, Hellack B, Kelly FJ, et al. (2015) Associations between three specific a-cellular measures of the oxidative potential of particulate matter and markers of acute airway and nasal inflammation in healthy volunteers. Occup Environ Med 72: 49-56. 